\title{
Investigation of Some Properties of Working Suspensions based on a Fine-dispersed Binder
}

\author{
Bazhenova O.Yu. ${ }^{1, a}$ \\ 1129337, Yaroslavskoye Shosse, 26, Moscow State University of Civil Engineering (NRU MGSU), \\ Department of Technologies of Cohesive Materials and Concretes, Russia \\ atvvib@mgsu.ru
}

\begin{abstract}
Keywords: fine-dispersed binder, fly ash, silica fume, activated bentonite
Abstract. This article considers the issues of the application of fine-dispersed mineral powders, which, in general, are used as active mineral additives or inert fillers for binders. It is known that the presence of such fine particles in the binder provides its denser packaging, increases the degree of constraint of the water-cement paste and the resistance to segregation, and in case of combination with the super- or hyperplasticizer its increases fluidity of the mixture. It is shown that finedispersed additives with hydraulic activity and developed specific surface, in addition, accelerate hardening and increase the strength of paste matrix and concrete. The possibility of using aqueous suspensions of particularly finely dispersed binders for impregnating loose or low-strength porous structures to increase the operational physical and mechanical loads was investigated. Also, the efficiency of using water-base cement suspensions of particularly fine-dispersed binders to impregnate loose or low-strength porous structures to increase the operational physical and mechanical loads. In the article we are presented results of the investigation of the physical and mechanical characteristics of working suspensions based on a fine binder used for injection solutions for the restoration of concrete and reinforced concrete structures, as well as for fixing soils, hydraulic engineering and underground structures, and the introduction of mineral additives into. Also, method of determining the viscosity and sedimentation (water segregation) of working suspensions, as well as their strength characteristics. Based on the results of the experimental investigation, optimal dosages of additives were chosen in order to reduce the binder's consumption and increase the characteristics of working suspensions based on a finely dispersed binder.
\end{abstract}

\section{Introduction}

The beginning of the twenty-first century was characterized by significant achievements in the technology of concrete. New effective binders, fillers and active mineral admixtures, reinforcing fibers, new technological methods of building composites have appeared and are widely used. In recent years, our knowledge on the properties and structure of concrete, processes of structure formation, has been significantly enriched $[1,2]$.

In our time, there is a gradual replacement of conventional traditional binders and concretes with multicomponent systems. Chemical modifiers of the structure, properties and technological characteristics of concrete are used in the latter, including complex modifiers, sometimes several dozen individual chemical additives, active mineral components of different dispersity (from 2000 to $25000 \mathrm{~cm}^{2} / \mathrm{g}$ ) and, in some cases, composite astringents, expanding additives (inorganic and organic), disperse fibrous fillers, as well as other special components. The multicomponent nature of the concrete mix allows to effectively control its structure formation at all stages of the technology and to obtain materials with the most diverse complex of properties [3-6].

At the same time, the multicomponent system increases the requirements for dosing of materials both at the stage of cement production and mixing the concrete mix, since it is often necessary to introduce a modifiers in very small quantities and mix highly dispersed powders to a homogenous mass, which can be achieved only through the use of appropriate equipment [7-9]. In recent years, interest in fine mineral powders has increased significantly in the technology of binders and concretes, which are mainly used as active mineral additives or inert fillers to cements [10-11]. It is possible to provide a more optimal particle size distribution of cement binder, by increasing the 
proportion of particles with sizes from 0.01 to 4.0 - 5.0 microns, which in ordinary Portland cement is no more than $30-35 \%$ with a predominant number of particles from 1.0 to $5.0 \mu \mathrm{m}[10,12]$.

The presence of such fine particles in the cement ensures its dense packaging, increases the cohesiveness of the cement paste and the resistance to segregation and increases flow ability of the mixture in combination with a superplasticizer. Finely dispersed additives with hydraulic activity and developed specific surface accelerate hardening and increase the strength of cement stone and concrete $[8,13,14]$. It is important to use dilute aqueous suspensions of particularly finely dispersed binders to impregnate loose or low-strength porous structures, for example sand, clastic or fractured soils, as well as stone and concrete structures whose bearing capacity has been reduced under the influence of operational physical and mechanical loads. In the first case, a conglomerate capable of bearing increased loads from buildings or structures erected on it, will be obtained in the form of concrete, and in the second case, the load-bearing capacity of stone, concrete and reinforced concrete structures will be restored or even increased [15-16].

At the end of the XX century, the highly-dispersed mineral binder called Microdur, intended for the preparation of injection suspensions (which, due to the optimally selected fractional composition, has a high penetration ability), appeared on the construction market [17-19]. The behavior of working suspensions based on Microdur was considered when small amounts of various fine active mineral additives introduced into it. This would reduce the cost of suspensions based on this binder without reducing its quality.

\section{Methods and Materials}

Microdur R-X with a specific surface area of about $2200 \mathrm{~m} 2 / \mathrm{kg}$ and the following granulometric composition: the content of particles smaller than $2 \mu \mathrm{m}-45 \%$, less than $4 \mu \mathrm{m}-80 \%$, less than $6 \mu \mathrm{m}$ - 95\%; Fly ash with an average specific surface area of about $500 \mathrm{~m}^{2} / \mathrm{kg}$, formed during the burning of Kuznetsky hard ash coal; silica fume with an average specific surface area of about $2000 \mathrm{~m}^{2} / \mathrm{kg}$; Activated (sodium) bentonite JSC "Khakassky" were chosen for the experiment. The studies were carried out on working suspensions with a water-binder ratio (W/B) of 2.0. The fly ash, silica fume, activated bentonite were introduced in an amount of 4, 8 and 12\% together with the binder in the aqueous medium. Suspension was mixed using a high-speed electric drill (more than $2800 \mathrm{rpm}$ ) as an actuator with an activator similar to the activator for oil-bound paints.

Since Microdur is mainly used in the form of injection solutions for the restoration of concrete, reinforced concrete and stone structures in dry conditions, as well as for fixing soils, foundations, hydraulic and underground structures, the main indicators for working suspensions are viscosity and sedimentation (water separation). The "conventional" viscosity was determined from the rate of flow of the suspension in seconds using the Marsh funnel. The sedimentation of the suspension was measured at a temperature of $210^{\circ} \mathrm{C}$ in standard cylinders with $1 \mathrm{~L}$ volume. The strength of samples was determined as follows. Quartz sand was poured into $40 \mathrm{~mm}$ cubic forms mounted on a platform type vibrator and compacted for 60 seconds. Then, when the vibrator was turned on (imitating the impregnation of the soil) a suspension was fed into the molds until they were completely filled. The obtained samples, stored in air-wet conditions, were tested for compression strength at the age of 3 and 28 days.

\section{Results and Discussion}

At $\mathrm{W} / \mathrm{B}=2.0$ "conventional" viscosity of working suspension should be 35 seconds for the examined type of binder. The deviation of the values is allowed within \pm 1 second. The results of determining the viscosity are given in Table. 1. 
Table 1 - The influence of mineral admixtures on suspension viscosity

\begin{tabular}{|c|c|c|c|}
\hline $\begin{array}{l}\text { № of } \\
\text { mix }\end{array}$ & Admixture type & $\begin{array}{c}\text { Amount of admixture, } \\
{[\%]}\end{array}$ & Viscosity, [sec] \\
\hline 1 & - & - & 35,2 \\
\hline 2 & \multirow{3}{*}{ Fly ash } & 4 & 34,8 \\
\hline 3 & & 8 & 34,8 \\
\hline 4 & & 12 & 35,2 \\
\hline 5 & \multirow{3}{*}{ Silica fume } & 4 & 36 \\
\hline 6 & & 8 & 41 \\
\hline 7 & & 12 & 43 \\
\hline 8 & \multirow{3}{*}{ Activated bentonite } & 4 & 37,5 \\
\hline 9 & & 8 & 43,8 \\
\hline 10 & & 12 & 55,5 \\
\hline
\end{tabular}

With the introduction of fly ash, the values of the "conventional" viscosity are within the limits permitted by the regulations, at any dosage. With the introduction of silica fume in an amount of $4 \%$, the viscosity remains within normal limits. A higher value of silica fume increases the viscosity to 41-43 seconds, which is not permissible. This can be explained by increased foaming of the suspension. Therefore, when using silica fume, it is necessary to add additives that prevent foaming.

With the introduction of activated bentonite, all values of the "conventional" viscosity go beyond the norm and are 37.5 - 55.5 seconds, depending on the dosage. When the bentonite placed into the water solution, the water penetrates through the interlayer space of the montmorillonite, which causes the hydration of the latter, and as a result, swelling occurs. With further dilution, bentonite is able to form a viscous suspension in which thixotropic properties are pronounced. In addition, montmorillonite has a rather high adsorption. Therefore, chemical additives-diluents must be introduced into the working suspension with addition of activated bentonite

As already mentioned, the second main indicator of working suspensions is their "viability", which is determined by sedimentation. The quality of the Microdur suspension is normal if sedimentation of the suspension at $210^{\circ} \mathrm{C}$ with $\mathrm{W} / \mathrm{B}=2.0$ does not exceed $8.54 \%$ within 60 minutes after its mixing. The results of the examination of sedimentation of suspensions with various additives are given in Table. 2.

Table 2 - The influence of mineral admixtures on sedimentation of suspension

\begin{tabular}{|c|c|c|c|c|c|c|}
\hline \multirow{2}{*}{$\begin{array}{c}\text { № of } \\
\text { mix }\end{array}$} & \multirow{2}{*}{ Admixture type } & \multicolumn{5}{|c|}{ Water segregation, [\%, after] } \\
\cline { 3 - 7 } & & 30 min. & 60 min. & 90 min. & 120 min. & 24 hours \\
\hline 1 & - & 2,4 & 3,6 & 4,8 & 6 & 7,85 \\
\hline 2 & \multirow{3}{*}{ Fly ash } & 2 & 3,6 & 4,4 & 5,6 & 8 \\
\hline 3 & & 3,2 & 6 & 8,8 & 11,2 & 15,2 \\
\hline 4 & & 3,3 & 5,1 & 6,7 & 7,8 & 16 \\
\hline 5 & \multirow{3}{*}{ Silica fume } & 5,6 & 6,4 & 7,2 & 8 & 10 \\
\hline 6 & & 6,4 & 7,2 & 8 & 8,6 & 10 \\
\hline 7 & & 0,8 & 1,2 & 1,6 & 2 & 4,8 \\
\hline 8 & \multirow{3}{*}{$*$} & 4 & 4,4 & 4,8 & 5,2 & 8 \\
\hline 9 & \multirow{2}{*}{ Activated bentonite } & 0,8 & 1,6 & 2 & 2,4 & 7 \\
\hline 10 & & 0,4 & 0,8 & 1,2 & 1,6 & 6 \\
\hline
\end{tabular}

Investigation of the effect of active mineral additives on sedimentation of suspensions showed that regardless of the amount of additives, the water segregation of the suspension is less than the 
maximum permissible. With the introduction of $12 \%$ fly ash, the greatest water segregation of $16 \%$ at the age of 24 hours is observed, and with the introduction of $12 \%$ silica fume - the smallest, which is $4.8 \%$. The presence of activated bentonite in the amount of $4 \%$ slightly increases the sedimentation at the age of 1 and 24 hours, and in the amount of 8-12\% significantly reduces the water segregation at both the age of 1 hour and 24 hours. With time the greatest water segregation is observed in suspensions that have fly ash in their composition, the lowest value is for compositions with activated bentonite. The results of compressive strength tests are shown in Table. 3.

Table 3 - Physical properties

\begin{tabular}{|c|c|c|c|}
\hline \multirow{2}{*}{$\begin{array}{ll}\text { № } & \text { of } \\
\operatorname{mix} & \end{array}$} & \multirow{2}{*}{ Admixture type } & \multicolumn{2}{|c|}{ Compressive strength (Rcomp), [MPa, at age of $]$} \\
\hline & & 3 days. & 28 days. \\
\hline 1 & - & 3,71 & 9,78 \\
\hline 2 & \multirow{3}{*}{ Fly ash } & 3,23 & 9,65 \\
\hline 3 & & 3,2 & 8,85 \\
\hline 4 & & 3,0 & 8,1 \\
\hline 5 & \multirow{3}{*}{ Silica fume } & 3,2 & 9,70 \\
\hline 6 & & 2,31 & 7,36 \\
\hline 7 & & 2,13 & 5,73 \\
\hline 8 & \multirow{3}{*}{ Activated bentonite } & 3,1 & 9,72 \\
\hline 9 & & 2,66 & 8,82 \\
\hline 10 & & 2,14 & 6,35 \\
\hline
\end{tabular}

The results of experiment shows that when a $4 \%$ of fly ash is introduced, the strength in comparison with the control samples remains practically unchanged both at the age of 3 days and at the age of 28 days. Introduction $8-12 \%$ of fly ash reduces strength at the age of 3 and 28 days by $1.0-1.7$ $\mathrm{MPa}$. The introduction of silica fume or activated bentonite in an amount of $4 \%$ also does not affect the strength of the samples. The addition of silica fume in an amount of $8-12 \%$ leads to a marked drop in strength, which is explained by the large foaming during the preparation of the slurry. The addition of $8 \%$ activated bentonite at the age of 3 and 28 days causes a decrease in strength by 1.0 $\mathrm{MPa}$, and the presence of activated bentonite in an amount of $12 \%$ causes a significant decrease in the strength of the samples at all times of hardening.

\section{Conclusions}

Analyzing the test results, we can draw the following conclusions:

- "conventional" viscosity of the working suspension is within the limits of admissible values when introducing these additives within range of $4 \%$; Fly ash can be administered in an amount up to $12 \%$;

- the content in the working suspension of additives in the amount of 4-12\% does not negatively affect its sedimentation; When considering the kinetics of water segregation, it can be seen that the greatest sedimentation is observed in suspensions containing ashes in their composition, and the lowest in compositions with activated bentonite;

- at the design age, the binder strength at the content of mineral additives in the amount of $4 \%$ practically does not differ from the control composition, and when $8 \%$ of the fly ash or activated bentonite is introduced, it decreases insignificantly.

Thus, according to the results of experimental studies, a positive effect of the introduction of these mineral additives in an amount of up to $4 \%$ on the properties of a very fine-fractioned binder Microdur is established, and the fly ash content can be increased to $8 \%$. This will reduce the cost of repair work without deteriorating their quality.

\section{References}

[1] Yu.M. Bazhenov, V.R. Falikman New century: new efficient concrete and technology: BuildInfo, \#1-2, (2007), pp. 289-290. 
[2] S.I. Bazhenova, L.A. Alimov High-quality concretes using industrial wastes: Bulletin of MGSU, \#1, (2010), pp. 226-230.

[3] S.I. Bazhenova Concrete of high operational reliability: Technology of concrete, \# 9-10, (2011), pp. 14-15.

[4] M.O. Korovkin Application of industrial waste in the technology of self-compacting concrete: Education and science in the modern world. Innovation, \# 6-2, (2016), pp. 226-234.

[5] V. Egorov High-rise Moscow: Building science of Moscow, \#2, (2007), pp. 14-18.

[6] S. Nikolaev High-rise buildings in Moscow. Safety and reliability is a complex of high-profile solutions: Security technologies and engineering systems (TB \& IS), \#1, (2006), pp.16-20.

[7] M. Schneider, Z. Betsner Economic and technical advantages of composite cements: Cement and its application. \# 3, (2016), pp 36-39.

[8] V.I. Kalashnikov, O.V. Suzdaltsev, R.A. Dryanin, G.P. Sekhposian The role of disperse and fine-grained fillers in new-type concretes: News of Higher Education Institutions. Building, \#7, vol.667, (2014), pp. 11-21.

[9] D.Ch. Nguyen Dinh Chinh, T.B. Nguyen The Vinh, Yu.M. Bazhenov High-strength concretes with complex application of ash of rice husks, fly ash and superplasticizers: Vestnik of MGSU, \#1, (2012), pp. 77-82.

[10] G.I. Berdov, N.I. Nikonenko, L.V. Ilyina Influence of highly disperse mineral additives on the mechanical strength of cement stone: Izvestiya Vysshikh Uchebnykh Zavedenii. Building, \#12, (2011), pp. 25-30.

[11] L.A. Urhanova, V.E. Rosina High-strength concrete with the use of fly ash and microsilica: Bulletin of the Irkutsk State Technical University, \# 10, vol.57, (2011), pp.97-100.

[12] G.A. Fokine, N.G. Vilkova, A.S. Guskov Influence of the particle sizes and their mass content in the initial suspension on the strength of cement stone: News of Higher Educational Institutions. Building, \#2 (662), (2014), pp. 11-16.

[13] O.Yu. Bazhenov, S.I. Bazhenova, M.I. Bazhenov Investigation of some properties of cements with a finely dispersed additive: Young Scientist, \#10, (2013), pp. 96-97.

[14] O.Yu. Bazhenova, V.E. Kaushansky Use offly ash at the Novosibirskaya CHPP in the production of Portlandcement: Construction and finishing materials. Standards of the XXI century XIII International Workshop of ATAM. Novosibirsk, (2006), pp. 87-93.

[15] S.V. Alekseev Microdur - Injection mineral knitting and experience of its application / International scientific and technical conference "Technologies, equipment, materials, regulatory support and monitoring for tunnel construction and underground parts of high-rise buildings". Moscow: Tunneling Association of Russia, (2006), pp.198 - 200.

[16] D.Z. Kochev Features of engineering and geological surveys and experience of increasing the bearing capacity of contaminated soils in urban conditions of the Moscow region: Sat. Sergeevsky readings. Engineering geology and geoecology. Fundamental problems and applied problems Anniversary conference dedicated to the 25th anniversary of the formation of IGE RAS. (2016), pp. 305-309.

[17] Lanis A.L. Diagnostics and quality control of hardening of soil massif by pressure injection method: Bulletin of the Siberian State University of communication, \#23, (2010), pp. 98-101.

[18] Baidakov, O.S. Application of materials of "Microdur" for injection works with strengthening of soils and reinforcement of structures: Metro and tunnels, \#6, (2005), pp. 34 - 38. 
[19] Panchenko A.I, Kharchenko I.Ya. Especially finely dispersed mineral knitting "Microdur": properties, technology and prospects of use: Building materials, \#10, (2005), pp. 76 - 78. 